\title{
The influence of driving pattern on pollutant emission and fuel consumption of hybrid electric vehicle
}

\begin{abstract}
Hybrid electric vehicles (HEVs) have an increasing presence in passenger transport segment. They have been designed to minimize energy consumption and pollutant emission. However, the actual performance of HEVs depends on the dynamic conditions in which they are used, and vehicle speed is one of the key factors. A lot of excess emission and fuel consumption can be attributed to rapid changes of vehicle speed, i.e. accelerations and decelerations. On the other hand, dynamic driving favours energy recovery during braking. This study examines the relationship between HEVs speed, pollutant emission and fuel consumption. The considerations were based on the results of testing vehicles in WLTC and NEDC driving cycles, performed on a chassis dynamometer. The test objects were two light-duty passenger vehicles, one with series-parallel, gasoline-electric hybrid system and the other, used as a reference, with conventional sparkignition engine. Both vehicles had similar technical parameters and combustion engines supplied with gasoline. The driving cycles were divided into several parts according to the speed range. For each part, pollutant emission and fuel consumption were determined and appropriate values of selected parameters of driving pattern were calculated. Combining the results of empirical research and calculated parameters allowed to obtain characteristics. Their analysis provided valuable insight into the impact of driving pattern on actual emission and fuel consumption of $\mathrm{HEV}$.
\end{abstract}

Key words: hybrid electric vehicle, HEV, pollutant emission, fuel consumption, driving pattern

\section{Introduction}

With the rapid development of world transportation, environment pollution and the depletion of non-renewable energy resources have become two serious problems. The need to address these concerns led many academic institutions and automobile manufacturers to adopt research and development programs that included not only more efficient and cleaner ways to use fossil fuel in internal combustion engine vehicles (ICEVs), but also the development of alternative propulsion systems and energy carriers. In recent years, battery electric vehicles (BEVs) have received increased attention worldwide and their production numbers for large markets has increased. However, despite remarkable achievements in the development of BEVs in the last years [5], there are still two serious problems to be solved: low operational range of BEVs due to relatively limited capacity of batteries and considerably high vehicle and battery costs, which reduces the number of potential buyers.

BEVs and ICEVs features are combined in hybrid electric vehicles (HEVs), with the variety of subtypes available, including plug-in hybrid electric vehicles (PHEVs). HEVs usually consist of two different power sources - an internal combustion engine and an electric motor. Some powertrain configurations of HEVs enable them to switch between two power sources, which allows for the use of pure electric mode under certain driving conditions or in low-emission zones of city centers. HEVs certainly do not have the operational range restriction of $\mathrm{BEV}$ s and they are beneficial in terms of environmental impact due to reduction in tailpipe emissions and fossil fuel consumption [8-10]. In the case of PHEVs there is also potential to diversify transportation energy sources and stimulate real opportunities on the integrating renewable energy into the power system. On the other hand, two separate power sources increase vehicle mass, which in turn lead to a higher consumption of both electricity and fuel.
The actual performance of HEVs depends on the dynamic conditions in which they are used [8-10], and vehicle speed is one of the key factors. A lot of excess emission and fuel consumption can be attributed to rapid changes of vehicle speed, i.e. accelerations and decelerations. On the other hand, dynamic driving favors energy recovery during braking.

The present study aims at investigating the impact of driving pattern on pollutant emission and fuel consumption of HEVs. It involves empirical testing of two light-duty vehicles - HEV with series-parallel hybrid system and ICEV with conventional spark-ignition combustion engine - on a chassis dynamometer in the WLTC and NEDC driving cycles.

\section{Parameters of driving pattern}

Vehicle driving pattern is usually defined by the variation of vehicle speed with time [5]. Some researchers extend this definition to other factors like gear changing, driving distance etc. $[6,12]$. It is possible to quantify driving patterns using certain parameters, also known as zerodimensional or point characteristics [2-6]. A large number of such parameters has been proposed [6], Among them, those related to speed and acceleration are most often considered for investigating the influence of driving pattern on vehicle pollutant emission and fuel consumption [3, 4].

The examples of driving pattern parameters used in previous research works $[1,6,7,11]$ can be divided into five categories:

1. Average value, in relation to: speed, driving speed (excluding stops), acceleration, deceleration, driving time within one driving period (from start to stop), number of acceleration-deceleration changes (and vice versa) within one driving period, etc.

2. Time share, in relation to: stop $(\mathrm{v}=0)$, acceleration, deceleration, driving at constant speed, etc. 
3. Standard deviation, in relation to: speed, acceleration, deceleration, etc.

4. Relative and joint distribution, in relation to: speed, acceleration, deceleration, etc.

5. Complex parameters: relative positive acceleration, positive kinetic energy, product of the speed and acceleration, product of the squared speed and acceleration, average absolute value of product of speed and acceleration, number of stops per distance, etc.

One of the classic examples of employing driving pattern parameters to examine their influence on pollutant emission and fuel consumption is the research of Ericsson [6]. She collected driving data from a vehicle driven in urban conditions and used the results to determine the values of 62 independent parameters, including commonly used variables based on speed and acceleration as well as newly proposed variables related to engine rotational speed and gear changing. After statistical analysis of the results obtained, 9 parameters were found to have significant environmental effects [6].

\section{Materials and methods}

The general concept of this study was to obtain data on pollutant emission and fuel consumption of vehicles tested in driving cycles that simulate dynamic driving conditions on the chassis dynamometer. Next, values of the selected driving pattern parameters for the speed profiles of these driving cycles were determined. Combining the results of empirical research and calculated parameters allowed to obtain dependencies for pollutant emission and fuel consumption on driving pattern parameters.

Empirical part of the research concerned two vehicles:

- HEV, with a series-parallel drive system, consisting of spark-ignition combustion engine, electric motor and continuously variable transmission e-CVT,

- ICEV, with spark-ignition combustion engine and continuously variable transmission CVT.

HEV was treated as the main object of research, while ICEV served as a reference, to compare test results. Both vehicles had similar technical parameters and combustion engines supplied with gasoline (Table 1).

Table 1. Specifications of the vehicles tested

\begin{tabular}{|l|c|c|}
\hline \multicolumn{1}{|c|}{ Parameter } & HEV & ICEV \\
\hline $\begin{array}{l}\text { Combustion engine } \\
\text { displacement }\end{array}$ & $1798 \mathrm{~cm}^{3}$ & $1798 \mathrm{~cm}^{3}$ \\
\hline Maximum power & $90 \mathrm{~kW}$ at $5200 \mathrm{rpm}$ & $108 \mathrm{~kW}$ at $6400 \mathrm{rpm}$ \\
\hline Maximum torque & $142 \mathrm{~N} \cdot \mathrm{m}$ at $3600 \mathrm{rpm}$ & $180 \mathrm{~N} \cdot \mathrm{m}$ at $4000 \mathrm{rpm}$ \\
\hline $\begin{array}{l}\text { Combustion engine } \\
\text { compression ratio }\end{array}$ & 13 & 11 \\
\hline Fuel type used & Gasoline & Gasoline \\
\hline Fuel injection type & Multi-point (MPI) & Multi-point (MPI) \\
\hline Gearbox type & e-CVT & CVT \\
\hline
\end{tabular}

Vehicles were tested in two type-approval driving cycles: the Worldwide Harmonized Light Vehicles Test Cycle class 3.2 (WLTC) and the New European Driving Cycle (NEDC). The driving cycles were divided into parts according to the vehicle speed range - WLTC into four parts: low speed, medium speed, high speed and extra high speed, while NEDC into two parts: Urban Driving Cycle (UDC) and Extra Urban Driving Cycle (EUDC).

Driving cycles were performed in laboratory conditions on the chassis dynamometer at Motor Transport Institute in Warsaw. The tests were repeated several times for each vehicle, with the combustion engine warmed up. The influence of the cold engine start was outside the scope of the current study. For a detailed description of test conditions, refer to previous publications [8-10].

The results obtained included averaged values of:

- fuel consumption (Q), expressed in $\mathrm{dm}^{3} / 100 \mathrm{~km}$,

- road emission of: carbon dioxide $\left(\mathrm{CO}_{2}\right)$, total hydrocarbons (THC), nitrogen oxides $\left(\mathrm{NO}_{\mathrm{x}}\right)$ and carbon monoxide (CO), expressed in $\mathrm{g} / \mathrm{km}$.

In the second part of the study, the parameters of driving pattern were determined for each part of the driving cycle. The analysis involved:

- average speed $-\mathrm{v}_{\mathrm{AV}}[\mathrm{km} / \mathrm{h}]$,

- average acceleration $-\mathrm{a}^{+} \mathrm{AV}\left[\mathrm{m} / \mathrm{s}^{2}\right]$,

- average deceleration $-\mathrm{a}_{\mathrm{AV}}^{-}\left[\mathrm{m} / \mathrm{s}^{2}\right]$,

- relative positive acceleration - RPA $\left[\mathrm{m} / \mathrm{s}^{2}\right]$,

- average absolute value of the product of speed and acceleration $-|\mathrm{v} \cdot \mathrm{a}|_{\mathrm{AV}}\left[\mathrm{m}^{2} / \mathrm{s}^{3}\right]$,

- time share of vehicle stop $(v=0)-u_{\text {stop }}[\%]$.

The parameters listed above are regarded as relevant for experimental investigation and modelling of pollutant emission and fuel consumption of light-duty vehicles [6]. Vehicle's average speed is the basic parameter used to determine the characteristics of internal combustion engines under dynamic conditions, e.g. for the inventory of pollutant emissions and fuel consumption [2]. Average acceleration determines the demand for maximum engine torque, while average deceleration indicates the intensity of braking [5]. Besides, both average acceleration and average deceleration can be considered as criteria for an aggressive driving style. Relative positive acceleration is calculated as the integral of speed multiplied with positive acceleration and the time interval when the acceleration is positive, divided by the total distance of the drive [6]. Relative positive acceleration value is large for driving pattern that includes a lot of high power-demand accelerations and is found to increase fuel consumption [5]. The average value of absolute value of product of speed and acceleration can be interpreted as a measure of engine power output per unit mass of the vehicle [5].

In order to determine the characteristics of pollutant emissions and fuel consumption, their values were normalized to the highest value obtained for one of the vehicles in a given category (fuel consumption or road emission of each exhaust component). In this way, differences in values are clearly visible and at the same time it is possible to compare the characteristics for both vehicles in one graph, without losing information relevant for the qualitative assessment of the course of the given dependence.

\section{Results and discussion}

The dependence of normalized fuel consumption on individual parameters of driving pattern is shown in Fig. 1. The sets of points were approximated by second degree polynomial functions. 

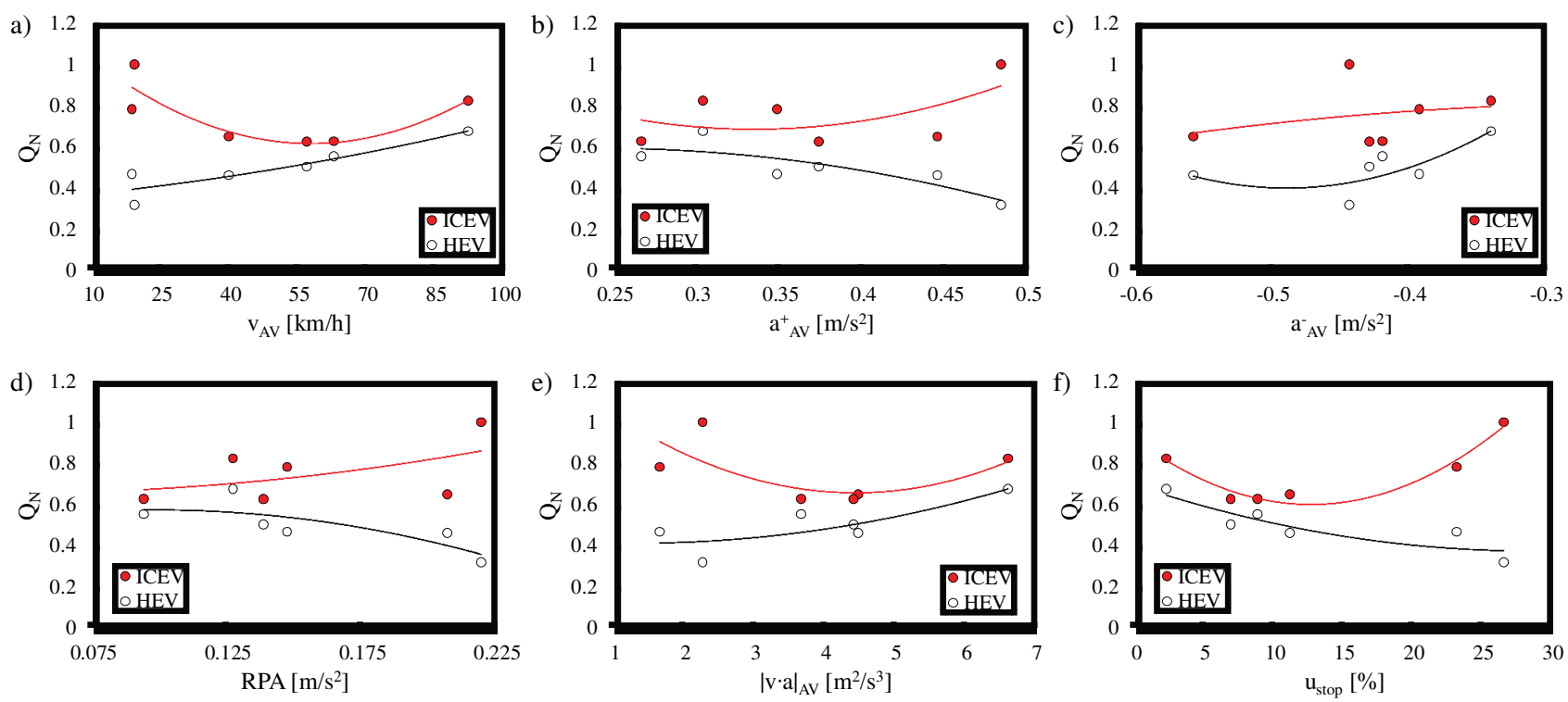

Fig. 1. The dependence of normalized fuel consumption on driving pattern parameters: average speed (a), average acceleration (b), average deceleration (c), relative positive acceleration (d), average absolute value of the product of speed and acceleration (e), time share of vehicle stop (f)

The dependencies of fuel consumption on the driving pattern parameters show considerable regularity along curves of approximation. By far the most effective parameters in this case are the average speed and time share of vehicle stop, followed by the product of speed and acceleration. On the other hand, average deceleration can be considered the worst parameter among those analyzed. Interestingly, smaller spread of points along the curves of approximation can be observed for $\mathrm{HEV}$, which may result from more stable operating conditions of the internal combustion engine in the hybrid system and lower sensitivity to dynamic states of operation than in the case of ICEV.

The characteristics determined for ICEV are consistent with those known from the literature [4-5] and databases implemented in specialized software such as INFRAS or COPERT. In principle, fuel consumption of ICEVs is high in heavy traffic conditions, characterized by low average vehicle speed, high time share of vehicle stop with engine working at idle speed and high dynamics of driving, as reflected in the frequent acceleration and deceleration. For $\mathrm{HEV}$ it is just the opposite, because at a low speed a significant part of the power used to drive the vehicle's wheels comes from the electric motor, hence the fuel consumption is low. In addition, in the dynamic driving conditions, the share of energy recovered by recuperative braking increases. Perhaps because of this the impact of the deceleration on fuel consumption is more pronounced for HEV than ICEV.

There is also a significant increase in fuel consumption of HEV and ICEV at high average speed, which corresponds to high engine load. This time, however, both the power generated by the electric motor and the intensity of recuperative braking are relatively low and do not allow a significant reduction in fuel consumption. Last but not least, high average speed implies low time share of vehicle stop, hence high fuel consumption observed.

For obvious reasons, the dependencies of normalized road emission of carbon dioxide are almost identical to those of normalized fuel consumption. Factors determining their courses are largely the same as those affecting fuel consumption. Hence, they were not presented here and included in the discussion.

The dependence of normalized road emission of total hydrocarbons on individual parameters of driving pattern is shown in Fig. 2. The sets of points were mostly approximated by second degree polynomial functions. A power function was proposed only for average speed, average acceleration (HEV) and average absolute value of the product of speed and acceleration.

Comparing the dependences obtained for the emission of total hydrocarbons to those regarding fuel consumption, it can be concluded that they are much less regular (which is understood as a large spread of points on the graphs). Average speed, average absolute value of the product of speed and acceleration and time share of vehicle stop can be assessed as moderately effective in the description of the total hydrocarbons emission. On the contrary, average acceleration, deceleration and relative positive acceleration are not useful in this application. These conclusions are valid for both HEV and ICEV.

Difficulties in outlining the trend regarding the dependence of hydrocarbons emission on driving pattern parameters indicates a high sensitivity of hydrocarbons emission to the operating states of the internal combustion engine. Nevertheless, these results confirm observations from other research works, e.g. [3], according to which road emission of hydrocarbons is the highest for low average speed (and therefore large time share of vehicle stop) and very low for high average speed (and low time share of vehicle stop) corresponding to high engine load.

The dependence of normalized road emission of nitrogen oxides on individual parameters of driving pattern is shown in Figure 3. The sets of points were mostly approximated by second degree polynomial functions. The exemptions were: average speed and average absolute value of the product of speed and acceleration, for which a power function was proposed, and time share of vehicle stop, for which an exponential function was used. 

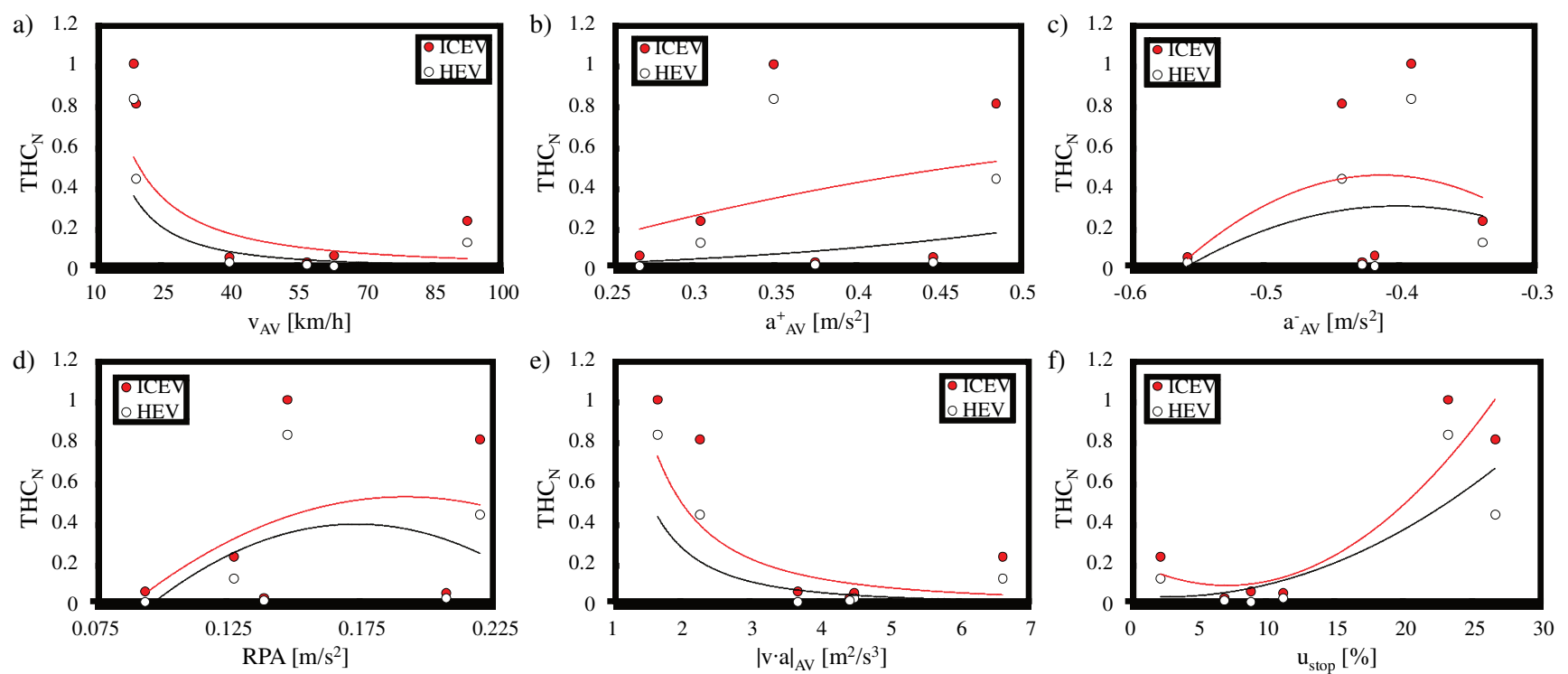

Fig. 2. The dependence of normalized road emission of hydrocarbons on driving pattern parameters: average speed (a), average acceleration (b), average deceleration (c), relative positive acceleration (d), average absolute value of the product of speed and acceleration (e), time share of vehicle stop (f)
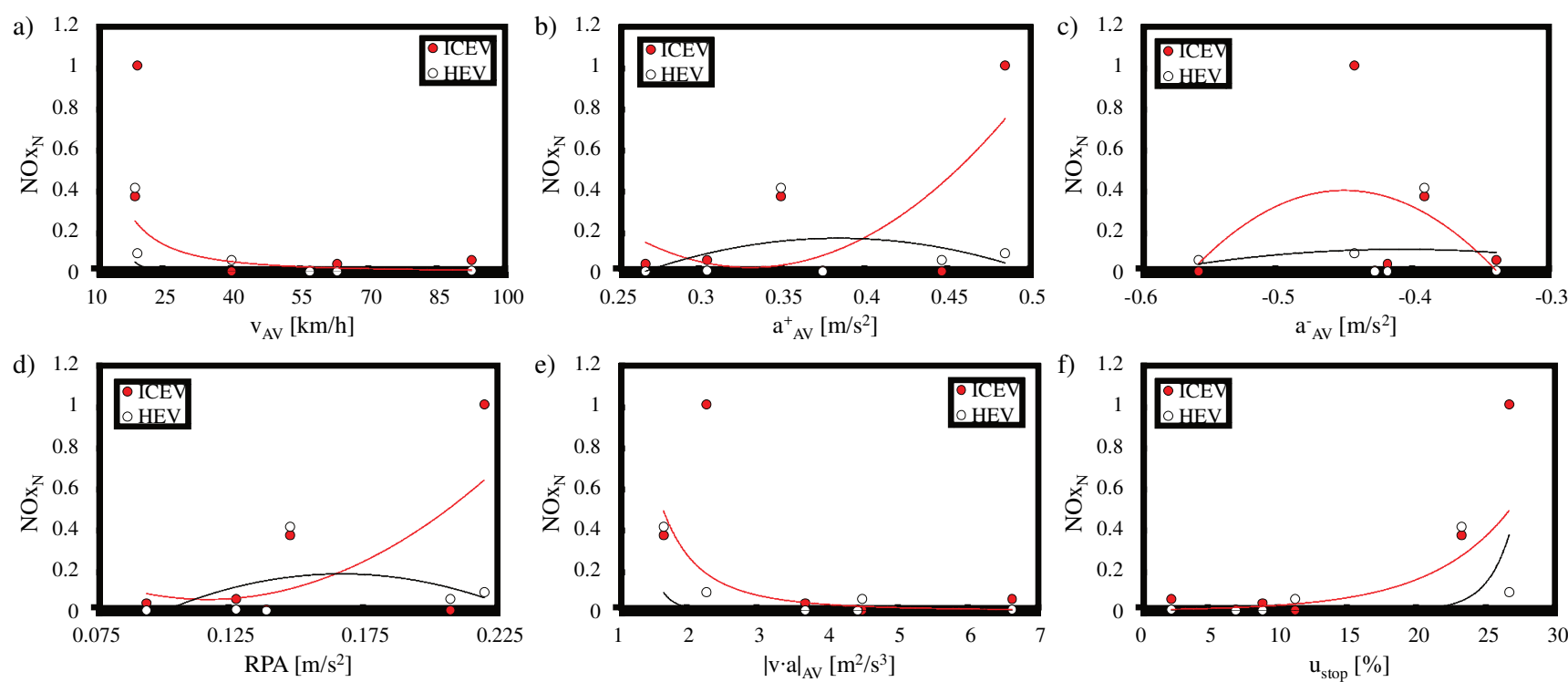

Fig. 3. The dependence of normalized road emission of nitrogen oxides on driving pattern parameters: average speed (a), average acceleration (b), average deceleration (c), relative positive acceleration (d), average absolute value of the product of speed and acceleration (e), time share of vehicle stop (f)

The relation of road emission of nitrogen oxides with driving pattern parameters should be assessed as relatively weak. For most of the parameters, the proposed approximation curve is for illustration only and does not allow to conclude on the relationship of parameters with the emission of nitrogen oxides. Only in the case of average speed, average absolute value of the product of speed and acceleration and time share of vehicle stop it is possible to determine the nature of dependence, at least to some extent. This is similar to the trends that have been discussed with reference to hydrocarbons emission.

It is worth noting that among all the pollutants that were included in this study, it is the emissions of nitrogen oxides that reached nearly the same values for both vehicles. The differences in values are very small, the only large discrepancy occurred for the 'low speed' part of the WLTC.
The dependence of normalized road emission of carbon monoxide on individual parameters of driving pattern is shown in Figure 4. The sets of points were approximated by second degree polynomial functions. The only exemption was the time share of vehicle stop, for which an exponential function was used.

When analyzing the shapes of dependencies plotted for carbon monoxide emission, differences may be noticed between results obtained for individual vehicles. The dependencies for HEV are regular and reveal some trends, whereas for ICEV there is a large spread of points, hence it is more difficult to draw the right conclusions.

Generally, the emission of carbon monoxide from HEV is much lower than from ICEV and is influenced by driving pattern. If the dependencies in Figure 5 did not apply to normalized values, this effect would be more clearly visi- 

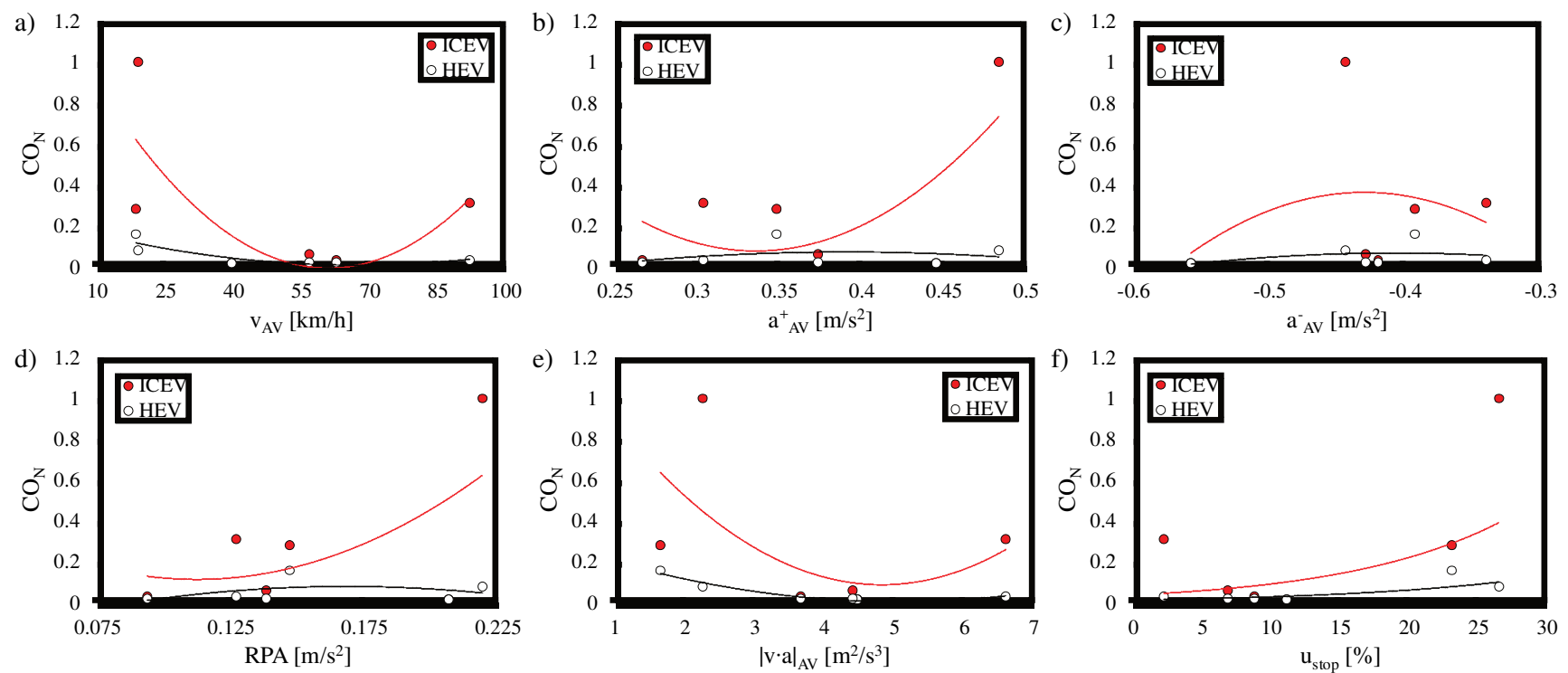

Fig. 4. The dependence of normalized road emission of carbon monoxide on driving pattern parameters: average speed (a), average acceleration (b), average deceleration (c), relative positive acceleration (d), average absolute value of the product of speed and acceleration (e), time share of vehicle stop (f)

ble. Starting from the average speed, i.e. the basic driving pattern parameter, the maxima of carbon monoxide emission for low and high speed values can be noticed. The largest emission is for low speed, which is confirmed in the literature $[3,4]$. The same applies to average absolute value of the product of speed and acceleration. This is reflected in the dependence determined for the time share of vehicle stop, which is high for low average speed (typical in urban traffic) and implies high carbon monoxide emission. For parameters related to acceleration and deceleration, a maximum carbon monoxide emission may be indicated for moderate values of these parameters.

In the case of ICEV, there are similar, but less accurate, trends observed in the relationships between carbon monoxide emission and average speed, average absolute value of the product of speed and acceleration, and time share of vehicle stop. However, dependences based on average acceleration, average deceleration and relative positive acceleration are rather difficult to interpret.

\section{Conclusions}

The impact of vehicle driving pattern on combustion engine's fuel consumption and pollutant emission is clearly visible and unquestionable. It is then possible to quantify this impact using statistical parameters of driving pattern, determined for a given course of vehicle speed over time. Such parameters are the most useful and effective to analyze trends in fuel consumption, but relatively less in the case of pollutant emissions.

The influence of driving pattern on fuel consumption and pollutant emission of HEV depends strongly on the structure of vehicle drive system and its control strategy. The decisive factor is the algorithm, according to which the electric motor assists the combustion engine, thus reducing pollutant emission and fuel consumption under certain driving conditions. Energy recuperation during braking, with intensity depending on the driving pattern, also has a significant impact. This makes HEVs different from ICEVs in terms of the influence of driving pattern on pollutant emission and fuel consumption, which has been confirmed by the results of this study.

\section{Nomenclature}

$\mathrm{a}^{+} \mathrm{AV}$ average acceleration

$\mathrm{a}_{\mathrm{AV}}^{-}$average deceleration

BEV battery electric vehicle

$\mathrm{CO}$ carbon monoxide

$\mathrm{CO}_{\mathrm{N}}$ normalized road emission of carbon monoxide

$\mathrm{CO}_{2}$ carbon dioxide

$\mathrm{CO}_{2 \mathrm{~N}}$ normalized road emission of carbon dioxide

CVT continuously variable transmission

EUDC Extra Urban Driving Cycle

HEV hybrid electric vehicle

ICEV internal combustion engine vehicle

MPI multi-point injection

NEDC New European Driving Cycle

$\mathrm{NO}_{\mathrm{x}}$ nitrogen oxides
$\mathrm{NO}_{\mathrm{xN}}$ normalized road emission of nitrogen oxides

PHEV plug-in hybrid electric vehicle

Q fuel consumption

$\mathrm{Q}_{\mathrm{N}} \quad$ normalized fuel consumption

RPA relative positive acceleration

THC total hydrocarbons

$\mathrm{THC}_{\mathrm{N}}$ normalized road emission of total hydrocarbons

UDC Urban Driving Cycle

$\mathrm{u}_{\text {stop }}$ time share of vehicle stop

$|\mathrm{v} \cdot \mathrm{a}|_{\mathrm{AV}}$ average absolute value of the product of speed and acceleration

$\mathrm{v}_{\mathrm{AV}} \quad$ average speed

WLTC Worldwide Harmonized Light Vehicles Test Cycle 


\section{Bibliography}

[1] ANDRÉ, M. Driving cycles development: characterisation of the methods. SAE Technical Paper 961112. 1996.

[2] CHŁOPEK, Z. Propozycja charakterystyk emisji zanieczyszczeń z silników spalinowych pracujących w warunkach dynamicznych. Archiwum Motoryzacji. 2009, 2, 111-134.

[3] CHŁOPEK, Z., BIEDRZYCKI, J., LASOCKI, J., WÓJCIK, P. Comparative examination of pollutant emission from an automotive internal combustion engine with the use of vehicle driving tests. Combustion Engines. 2016, 164(1), 56-64.

[4] CHŁOPEK, Z., BIEDRZYCKI, J., LASOCKI, J., WÓJCIK, $P$. Investigation of pollutant emissions from a motor vehicle engine in tests simulating real vehicle use in road traffic conditions. Combustion Engines. 2013, 154(3), 202-207.

[5] CHŁOPEK, Z., LASOCKI, J., WÓJCIK, P., BADYDA, A.J. Experimental investigation and comparison of energy consumption of electric and conventional vehicles due to the driving pattern. International Journal of Green Energy. 2018, 15(13), 773-779, DOI:10.1080/15435075.2018.1529571.

[6] ERICSSON, E. Independent driving pattern factors and their influence on fuel-use exhaust emission factors. Transportation Research Part D: Transport and Environment. 2001, 6(5), 325-345.

[7] FOMUNUNG, I., WASHINGTON, S., GUENSLER, R. A statistical model for estimating oxides of nitrogen emis-

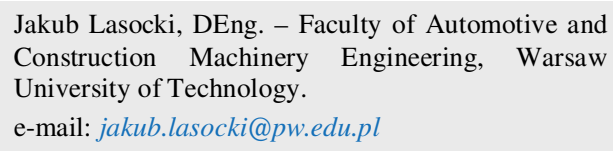

sions from light duty motor vehicles. Transportation Research Part D: Transport and Environment. 1999, 4(5) 333352. DOI:10.1016/S1361-9209(99)00013-9.

[8] GIS, M., BEDNARSKI, M. Comparative studies of harmful exhaust emission from a hybrid vehicle and a vehicle powered by spark ignition engine. IOP Conference Series: Materials Science and Engineering. 2018, 421042022. DOI:10.1088/1757-899X/421/4/042022.

[9] GIS, M., BEDNARSKI, M., WIŚNIOWSKI, P. Comparative analysis of NEDC and WLTC homologation tests for vehicle tests on a chassis dynamometer. Journal of KONES Powertrain and Transport. 2018, 25(3), 189-196.

[10] GIS, M., LASOCKI, J. Advantages of using hybrid vehicles based on empirical studies on the chassis dynamometer in the WLTC test. Journal of KONES Powertrain and Transport. 2018, 25(4), 103-109.

[11] KUHLER, M. KARSTENS, D. Improved driving cycle for testing automotive exhaust emissions. SAE Technical Paper 780650. 1978.

[12] NEUBAUER, J.S., BROOKER, A., WOOD, E. Sensitivity of battery electric vehicle economics to drive patterns, vehicle range, and charge strategies. Journal of Power Sources. 2012, 209, 269-277.

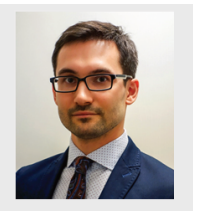

Maciej Gis, DEng. - Environment Protection Centre in Motor Transport Institute.

e-mail: maciej.gis@its.waw.pl 